morning there was some improvement in the symptoms. He again vomited in the afternoon. The pulse was frequent, not very strong and occasionally irregular. Milk with whisky and beef juice were given. One other dose of morphia was administered at $6: 40$ P.M. to relieve a very intense attack of pain, but after this it was not again required.

During the night the pain passed to the left side of the chest wall, and it was thought the attack would prove to be one of pleurisy on that side; a small blister was applied over the left infra-mammary region. The increase in the respirations and pulse and the continuance of fever gave grounds for believing that there was some new inflammatory process beginning in the chest. The pain and vomiting were thought to be reflex symptoms due to this cause and the subeequent progress of the case and its termination confirmed this opinion.

May 27. During the night the pulse had much less force, and food and stimulation were continued. There was no vomiting until 10:30 A.M. when a considerable amount of greenish fluid was thrown off.

Dr. Prentias met me in consultation and on examining the chest we discovered solidification in the recently expanded lung on the right side. There was a decided area of dullness, where the percussion had been almost normal two days before, and there was some bronchial breathing with bronchophony over the same area. The conclusion reached was that there had been an extension of the inflammatory process to the pulmonary tissue and that the symptoms present were due to pneumonia suddenly developed in the right lung.

The care which had been taken and the avoidance of any imprudence or exposure precluded the idea that this attack was the result of "catching cold;" the nature and course of the illness showed that it was not primarily connected with digestion and, therefore, not due to the indigestion of the food taken.

The alarming symptom was the weakness of the heart's action. During the morning the pulse ranged from 128 to 135 ; nitro-glycerin and digitalis were administered but with little effect in giving strength

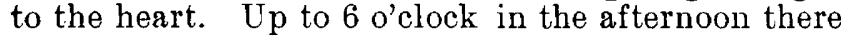
was no alarm felt as to any immediate danger; at this time the pulse became more frequent and feeble and the dyspnea was more marked. Strychnia and nitro-glycerin were given hypodermatically at regular intervals and stimulating enemata employed. At 9 P.M. there was such a marked collapse that death seemed imminent; transfusion with a sterilized saline solution was made into the median-cephalic vein of the right arm; three pints were introduced with the effect of bringing back warmth to the extremities and some color to the face, the pulse also became fuller and stronger; but this effect was temporary only and by 11 o'clock the same symptoms of collapse returned. From this time the change was rapid. Consciousness was not altered until within a short time of the last moment. Death occurred at $1: 15$ A.M., May 28.

Bellevue Hospital, New York.-The Commissioners of Charities and Correction of New York City have determined to introduce the novelty of Turkish and Russian baths into that institution. Bids thereon are to be opened June 27, and the work will be pushed.

\section{NOTES OF A CASE OF ACUTE SUPPURATIVE PANCREATITIS WITH REPORT OF NECROPSY.}

Read in the Section on Practice of Medicine, at the Forty-sixth Annual Meeting of the American Medical Association, at Baltimore, Mrd., May 7-10, 1895 .

BY I. E. ATKINSON, M.D.

PROFESSOR OF MATERIA MEDICA AND THERAFEUTICS AND OF CLINICAL MEDICINE IN THE UNIVERSITY OF MARYLAND. BALTIMORE. MD.

Acute suppurative inflammation of the pancreas is so rarely recognized during the lifetime of the paient, that I have thought that the details of the following case, in which it was possible to make a correct diagnosis while the patient was yet alive, would prove sufficiently interesting to engage your attention for a few moments.

I was called to see, on Dec. 2,1894, Mrs. S., the mother of two children, one 12 years, the other six months old. She was 35 years of age, with dark hair and eyes, tall and unusually stout, though it was thought she bad lost nearly forty pounds during her illness. She had enjoyed excellent health until fifteen months previously when she was seized with a severe attack of what her physician told her was hepatic colic, and which was followed by intense jaundice within two days. The attack lasted three weeks, with the usual symptoms. No gall stone was recovered from the feces, though looked for. The pain was almost constant, though of unequal severity. After a very severe paroxysm it disappeared abruptly and the patient soon regained her health. She became pregnant almost immediately after, nearly eleven years after her first and only other pregnancy. She was safely delivered last June, did not nurse her baby and made a good convalescence. In August she was thrown over the dashboard of a dog-cart but was apparently unhurt. During the summer, for a month or more, was affected with slight diarrhea. Upon the last day of September she was suddenly seized with an attack which she recognized as identical in character with her former attack of hepatic colic. After two days, her urine became dark, her stools colorless, and jaundice supervened. Her pain was almost incessant though she did not take to her bed. After a while the intervals between the paroxysms of pain became longer, but no positive relief in its intensity was obtained, though the jaundice diminished and her feces became colored again. She continued to lose weight, her appetite and strength failed and she finally took to her bed, about four weeks previous to my first visit. The various remedies employed under medical advice gave only temporary and partial relief. Since taking to bed, she had had no sharp paroxysms of colicky pains, but had had frequently recurring milder pain, with persistent, though slight jaundice, and frequent vomiting, the ejected matter occasionally being streaked with blood.

At the date of my first visit, sixty-two days after the beginning of the attack, she was in bed, alightly jaundiced; her body was still well nourished. Her tongue was coated with a thin yellowish fur. She had no sore throat. The heart and lungs gave no abnormal sign. There was no expectoration and no cough. She was vomiting several times daily, almost without nausea, a greenish fluid, sometimes slightly bloody. The vomiting appeared to have no relation to the ingesta. The bowels were moved several times daily. The actions were semi-solid, grayish, and 
contained lumps of mucus. This mild diarrhea and vomiting were said to have been present for several weeks. Hiccough had latterly been very troublesome. There was no splenic enlargement. Liver dullness began in the mammary line at the first rib, but did not extend beyond the costal arch. The body was somewhat distended with gas. In the epigastric region, extending into the left hypochondrium and reaching to within an inch and a half of the navel, was an induration, not modifying the outline of the abdominal wall, irregular in contour, not fluctuating, not movable, and but slightly tender to pressure; its diameter in the median line was about three inches and four and a half inches laterally, reaching to left mammary line. The percussion note over this tumor was relatively dull, not tympanitic. The lower abdomen showed no abnormality. The urine was abundant, darkened by bile pigment and faintly albuminous and with Fehling's solution gave a slight but positive sugar reaction. It was acid and of sp. gr. 1020. Though almost no pain was elicited by palpation, the patient complained of severe lancinating paroxysmal pain radiating from the epigastric region, with its point of greatest intensity under the xyphoid cartilage. She also suffered similar pain in the back, between the shoulders. The abdominal muscles remained almost motionless during respiration, which was almost purely costal and rapid, sig. nificantly so when considered with reference to the pulse rate and in the absence of signs of pulmonary disorder. Fever was said to have been present for many weeks, though recorded observations were not made until November 27. During the entire period of illness there had been no chill. Several weeks previously there had been a sensation of chilliness, but this had never recurred. Neither had there been sweating, except to a small extent about the head. She had at no time had symptoms of intestinal obstruction; on the contrary, there had been a notable tendency toward diarrhea almost constantly from the first. She was unable to lie upon either side and was most comfortable in a semi-recumbent, dorsal position. Exhaustion was great and sleep very insufficient and disturbed. An hour after my examination she vomited some fresh blood.

A consideration of all the symptoms and history seemed to justify the following diagnosis: hepatic colic at the outset of symptoms on September 30 ; impaction of the calculus at the common orifices of biliary and pancreatic ducts in the duodenum with incomplete obstruction. Inflammatory hyperemia with gradual formation of suppurative pancreatitis and peri-pancreatitis. The case progressed with varying but increasingly graver symptoms. The tumor gradually extended downward to the level of the navel. Diarrhea became very unmanageable, the stool assuming a thin grayish or greenish-gray, or yellowish, occasionally dark character. Free fat was never detected in them, though sought for diligently. Vomiting was also extremely distressing and constant, though often performed without nausea. Microscopic examination of vomited matters gave no information as relating to the nature of the essential trouble. They were largely made up of greenish mucus, often containing blood, or were often composed almost entirely of ingesta. Treatment, both of diarrhea and vomiting produced only temporary effect. There was complete anorexia. In spite of supporting and anodyne treatment the physical con- dition steadily deteriorated, and on December 12 Professor Tiffany was called in consultation with a view to operative interference. While agreeing in the main with the diagnosis as given, Professor Tiffany in view of the general condition did not feel justified in operating. Diarrhea, vomiting and paroxysmal pain now became very distressing and the patient was kept constantly mildly under the influence of morphin, hypodermically administered. The tumor remained hard, irregular, and gave no sign of fluctuation. Tympanitis had noticeably increased on the $14 \mathrm{th}$, and upon that date a noticeable fall of evening temperature was observed, hut there was no increase of abdominal tenderness, though paroxysms of pain were frequent and severe whenever the effects of the morphin became weakened. On the 16th, cough developed and crepitation was heard at the bage of the right lung. On the 18 th at $8: 45$ o'clock she became very weak, the face, feet and hands cold, the respiration slow. She rallied slightly after a while and during the day had four dark green stools. On the 19 th, at 9:45 o'clock A. M. she passed a copious stool consisting entirely of bloody pus. During the day she had several similar stools. At the same time the tumor became indistinct and noticeably smaller. She sank rapidly and died in collapse at 5 P. M. The course of the pulse, temperature and respiration and the extent of diarrhea are shown in the accompanying chart, which, however, dates only from the fiftyeighth day of the disease.

Post-mortem examination, by Dr. K. B. Batchelor, twenty hours after death. (Examination of abdomen only.) Abdomen distended and tympanitic. On opening abdominal cavity a large quantity of foul-smelling gas escaped with something of an explosion. Gas continued to escape for some seconds. Greater omentum contained a quantity of fat. There are multiple fresh adhesions between omentum and parietal peritoneum in superior portion of abdominal cavity, and there is also, here, very slight congestion in peritoneum. No fluid in peritoneal cavity. The adhesions (fine fibrous bands) are easily broken down and separated in right superior portion of omentum and peritoneal cavity. Toward the left side they gradually increase in number and size, but. are easily separated everywhere.

Areas of fat necrosis are found in great numbers in left upper side of omentum, over the abscess cavity. None are found on right side. The inferior portion of omentum is free from adhesions or fat necrosis. The posterior surface of the omentum and the transverse meso-colon are much congested and covered with recent fibrous adhesions. The intestines in superior portion of abdominal cavity are tied together by numerous fresh adhesions. They are easily separated.

Stomach shows nothing abnormal. The head of the pancreas is almost entirely obliterated, the part remaining forming a portion of the posterior wall of the pus cavity. This cavity occupies the position usually occupied by the pancreas, together with the whole of the lesser omental cavity. Its walls are shreddy and have a spongy, worm-eaten appearance. The cavity extends upward behind the stomach to the vault of the diaphragm, the inferior surface of the diaphragm being covered, to a less extent, with the shreddy and spongy lining of the pus cavity. Situated about the center of the lower portion of this cavity is a small remaining part of the pancreas. It. 
also is spongy and worm-eaten in appearance, and readily breaks down on pressure. Its meshes are filled with the contents of this cavity. It is connected to the wall of the cavity by a narrow pedicle. The cavity is filled with a thick, dark, reddish-brown, greasy-looking, very ill-smelling fluid, which is also greasy to the touch. On microscopic examination it
is found to be composed of pus corpuscles, red blood is found to be composed of pus corp
cells, fat cells and granular detritus.

An opening is found on the inside of the descending portion of duodenum (side next to abscess cavity) about the site of the opening of the common duct. It has very ragged edges. The source of the gas in occur spontaneously; the sloughing pancreas having
According to Fitz, whose classical writings upon acute pancreatic inflammations have done so much to render their clinical study definite, three varieties of acute pancreatitis are encountered: hemorrhagic, gangrenous and suppurative. Mild and favorable cases of hemorrhagic pancreatitis have not been detected during life, but post-mortem observation appears to prove that they may occur. Should death, in the more severe cases, not take place within the first week the inflammation merges into the gangrenous form, which seems an almost invariably fatal course in from three to eight weeks. Recovery may
occur spontaneously; the sloughing pancreas having

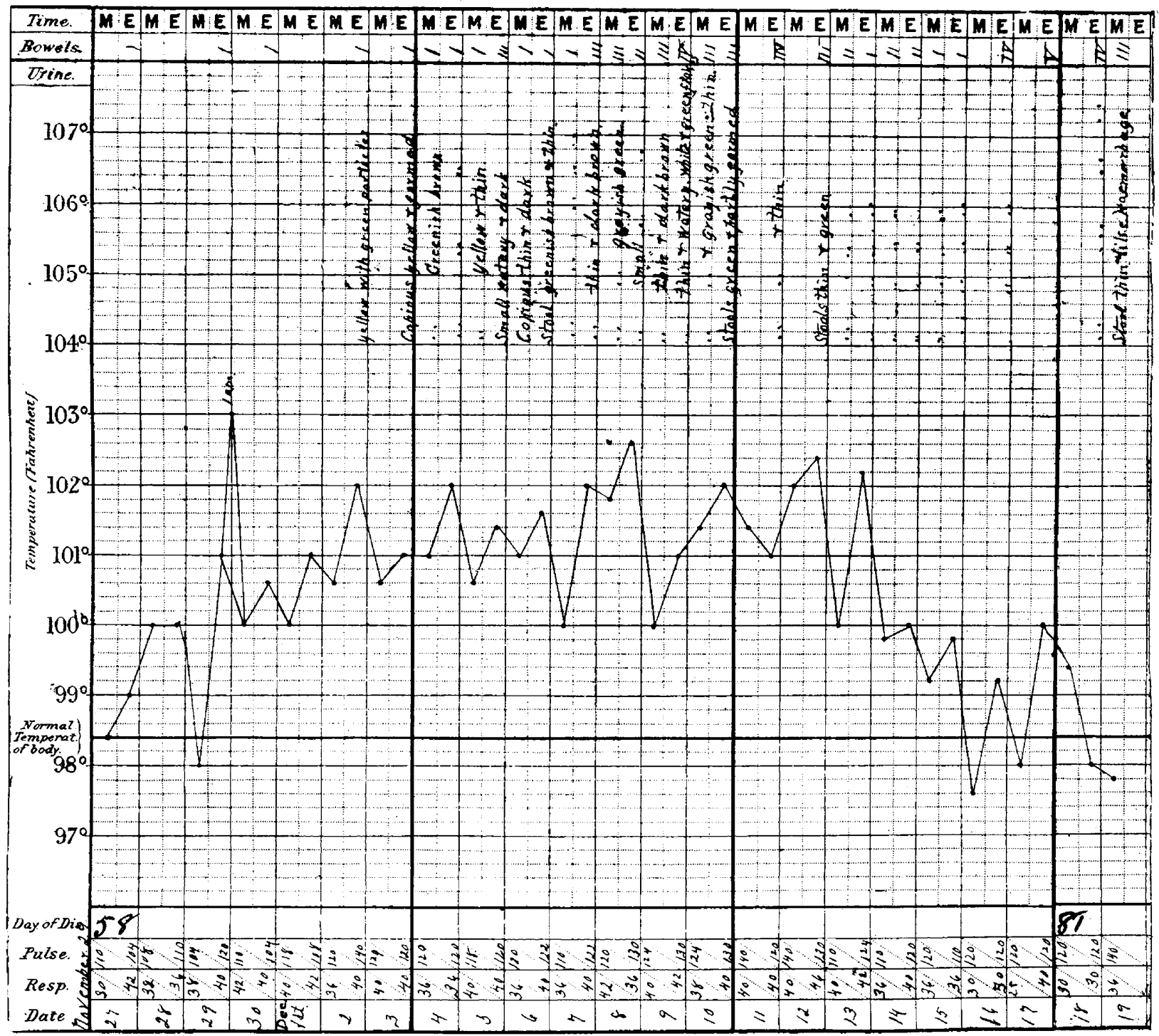

the peritoneal cavity was not discovered. None of been discharged through the bowels or after surgical the contents of the abscess had escaped into the operation.

larger peritoneal cavity. The peritonitis, which was Suppurative pancreatitis, Fitz separates from the very recent, had evidently begun during the last days two preceding forms. Not associated with hemorof life, probably on the 14th, when the sudden fall of rhage or gangrene, its tendency is toward pus formatemperature occurred, as shown in the chart. It is tion and death in from a few weeks to a year. A interesting that its development was not accompa- case recently reported by Thayer, however, shows nied by any increase of abdominal tenderuess. The that surgical interference, following early recognirupture of the abscess probably occurred upon the tion of the disorder, may be expected to reduce the day preceding death and was synchronous with the death rate materially (Bulletin of the Johns Hop. remarkable diminution in size and definiteness of kins Hospital, February, 1895), and though the clinthe abdominal tumor. ical diagnosis of either form of acute, pancreatitis 
has, heretofore, been wellnigh impossible, it may be hoped reasonably, that the more definite knowledge of their clinical history and symptomatology that we now possess will insure its very much more frequent recognition. The case that I have the honor to report presented characteristics that rendered an accurate diagnosis fairly easy to any one reasonably familiar with recent literature upon the subject. More exact acquaintance with acute pancreatitis, however, will probably reveal frequent inter-relations of all three varieties mentioned. My own case, for example, presented indisputable proofs of an antecedent hemorrhagic condition, as shown in the presence of blood cells and coloring matter in the contents and walls of the abscess cavity.

\section{STRABISMUS AS A SYMPTOM, ITS CAUSES} AND ITS PRACTICAL MANAGEMENT.

Read before the Michigan State Medical Society, June 7, 1895. BY LEARTUS CONNOR, M.D. DETROIT, MICH.

Landolt in his classical work says: "A strabismus operation, when undertaken without an exact knowledge of the optical and muscular functions of the eye, is but a rude and dangerous experiment." The reason for this statement springs from the fact that strabismus is merely a symptom of numerous pathologic and congenital defects, and its rational management calls for the study and removal, or correc. tion of these, so far as is practicable. The story of strabismus well illustrates the persistency by which the profession traces a symptom to its origin, in order that its cause may be removed and the symptom cured. Failure of squint operations has led to such study as revealed the reasons for the past de. fects and the methods for future success.

At present we know that some cases of squint are readily curable, that some are incurable, and others doubtful, calling for additional study ere they can be classed either as curable or incurable. Diefenbach operated first for convergent squint in 1839 , by dividing the belly of the internal rectus muscle. $\mathrm{His}$ operation was hased upon the analogy of operations upon contracted muscles in other portions of the body. He reasoned, that since division of contracted muscles or tendons elsewhere, restored muscular equilibrium, it should do so in the ocular muscles. He neglected to note that the problem of contracted ocular muscles differed radically from that presented elsewhere, in that opposing recti and their associated elastic tissues constantly tended to separate their divided ends. Hence the results obtained by him. self and others were so frequently disappointing and actually disastrous that, except for the radical change introduced by Bohm, the operation must have passed into merited oblivion. This transferred the site of the operation from the belly of the muscle to its tendinous insertion, thus leaving the capsule of Tenon mainly undisturbed. The technique of the operation was so perfected by von Graefe as to render it easy and safe of performance; especially useful was his method for either increasing the effects of a tenotomy or diminishing the same.

The ophthalmoscope enabled us to see that some cases of squint were due to diseases of the refractive portions of the eye, distorting the passage of the rays of light in their course to and from the retina, or, as in case of disease of the optic nerve, cutting off the power of transmitting the impression made by the rays of light upon the retiua, to the brain.

Not a few cases were traced to corneal opacities. Eyes entirely blind were found to often squint. Thus the symptom squint was traced to a variety of pathologic conditions, having one common feature, viz., they rendered the vision of the two eyes unequal and so deprived them of the "guiding sensation." With these facts in mind it is clear that a squint operation. without previous careful ophthalmoscopic examination, must be "a rude and dangerous experiment."

Donders' studies of refraction and accommodation traced this symptom to other and more common sources. Thus he showed that three-fourths of the cases of convergent squint were hyperopic, and an equal proportion of the cases of divergent squint were myopic. Healso pointed out the intimate relationship between convergence and accommodation, a physiologic fact which anatomic researches have supported, by demonstrating the close relation of their centers in the floor of the fourth ventricle. When the eyes accommodate for near objects by the contraction of the ciliary muscle, they also converge by the contraction of the internal recti. The bearing of this fact upon the causation of squint is apparent, when it is remembered that the hyperope is compelled to accommodate at all distances, and so the ciliary muscles are in a state of constant tension, and with them the internal recti. The flattened eyeball of the hyperope has broken the harmony which should exist between convergence and accommodation. Thus, if the hyperope accommodate for twelve inches, as in reading, the convergence will be at a point less than twelve inches if the muscles are of normal power. The result is a diffusion of impressions upon the retinæ, to escape which the squinting hyperope turns one eye in and fixes the other at twelve inches, ignoring the impression of the squinting eye. A repetition of such acts forms a squint habit, which, while at first alternating, at last usually becomes fixed. The habitual suppression of the image in the squinting eye is followed by a loss of the power of perception-a loss which can be repaired if the retinæ be normal at the first. Thus we have convergent squint due to eyes defective in the length of their antero-posterior axes. To the query, Why all hyperopes do not squint, it is replied that in those who do not squint, the normal balance between the power of the internal and external recti is so changed that, instead of being 4 to 1 it is less, only 2 to 1 or even 1 to 1 . Hence in the non-squinting hyeropes, the excessive converg. ence required for distinct vision is balanced by the weak interni, so that the eyes remain straight. If the externi be much in excess of the interni, we have a hyperope with divergent squint. In support of this view of the causation of squint, advanced by Valk, I have habitually found all hyperopes to have weakened interni, as measured by the standard of 4 to 1 .

Donders found that myopes needed little or no accommodation, because the eyeballs were already too long; hence the convergence in near geeing would be nil, and so if the strength of the recti was normal, the eyes would turn outward and give a divergent squint. But if the externi were weak the eyes might remain straight, or if very weak they might turn in and give a convergent squint. Aside from muscular action in causing divergent aquint in myopes, we 